Liberals and conservatives are (geographically) dividing Matt Motyl

University of Illinois at Chicago

To appear in P. Valdesolo and J. Graham's (Eds.), Bridging Ideological Divides. 


\section{Liberals and conservatives are (geographically) dividing}

Conservatives may not be from Mars and liberals may not be from Venus, but they are dividing into Red and Blue worlds. And this is increasingly so in recent decades. Despite the fact that most national elections are relatively close, where the winner prevails by a couple of percentage points, the United States of America is becoming increasingly the (not so) United Red and Blue States of America. This is most pronounced in smaller, more localized geographic units like neighborhoods and census tracts, where one party wins elections in a landslide and residents rarely communicate with people who hold differing political values (Bishop, 2009; Mutz, 2006). Blue communities are home to disproportionately many Democrats and Red communities are home to disproportionately many Republicans, and both these communities and the residents of these communities differ in many ways beyond simple partisan identification. For example, residents of blue communities are more likely to identify as "spiritual, but not religious," while residents of red communities are much more likely to identify as religious (Abramowitz, 2012). Similarly, 50\% of residents in Red America own guns, but only $19 \%$ of residents in Blue America own guns. Moreover, recent survey data suggests that lesbian, gay, bisexual, and transgender (LGBT) individuals report feeling stigmatized and they do not belong in red states where the majority of the population has supported banning same-sex marriage and forbidding non-heterosexuals from teaching in public schools (Lick, Tornello, Riskind, Schmidt, $\&$ Patterson, 2012). This sense of not belonging triggers selective migration to places where people feel that they are accepted and that they do belong (Motyl, 2014; Motyl et al., 2014). Some evidence even suggests that LGBT individuals may be fleeing red communities and heading for greener (or, more rainbow-patterned) pastures (Lewis, 2012; Smart \& Klein, 2013). With LGBT individuals emigrating from red communities, there are fewer opportunities for people in red communities to befriend LGBT individuals. These are just a few instances of a broader phenomenon of ideological migration that has resulted in the growing segregation of Red America and Blue America.

In this chapter, I propose Ideological Enclavement Theory to explain how Red and Blue America emerged and what the consequences of living in these ideologically-segregated enclaves are. This theory identifies two primary antecedent causes. First, people have gut-level intuitions about the ideology of different enclaves, and when the ideology of a community matches people's personal ideology, people infer that they would fit in that community. Second, when people have the opportunity to do so, they will selectively migrate into enclaves that share their ideology. This ideological migration process operates to satisfy basic psychological needs, like the need to belong and a sense of physical security, and to pursue higher-level psychological goals, like self-transcendence. These consequences of satisfying these personal psychological needs fall into three main categories. First, at the individual level, people in fitting enclaves should experience greater well-being, less uncertainty about their understanding of the world, and better physical health. Second, at the within-community level, the enclaves with a relatively more homogeneous ideology should exhibit higher levels of cooperation, social capital, social support, and trust. Third, at the between-community level, intergroup relations between these opposed ideological camps should be characterized by conflict, demonization, hostility, prejudice, and violence (see Figure 1). I review each of these hypotheses in detail next.

\section{Homophily and Enclavement}

People surround themselves with people similar to them. Generally, the more similar our neighbors are to us, the better. This tendency toward homophily (love of the same) is pervasive 
and reliable, yet little is known about why homophily happens (for a review, see McPherson, Smith-Lovin, \& Cook, 2001). Whites tend to live in communities with more whites; blacks tend to live in communities with more blacks (Durrheim \& Dixon, 2003; Schofield, 1995). While racial and ethnic homophily have been the most extensively studied, it appears along numerous other lines, too. For example, Sunni Muslims tend to live in communities with more Sunni Muslims; Shi'a Muslims tend to live in communities with more Shi'a Muslims (French, Purwono, \& Triwahyuni, 2011; Park, 2012). Jews create social networks with forty times as many Jews as would be expected given the percentage of the total population that they comprise (Fischer, 1977). These social groups are relatively fixed and have a long history, so they may not be optimal cases for learning much beyond the apparent fact that we like to be similar to those around us.

By looking at the behavior of more fluid groups with shorter histories, we can get a closer look at how homophily emerges. In extreme cases, groups are told that they do not belong and they relocate en masse to promote their survival. For example, the Church of Latter Day Saints spent its first fifty years of existence as a highly mobile group, being told that they did not belong and being subjected to violent attacks from residents of their temporary homes until finally settling in the largely uninhabited mountains of Utah (Bushman, 2005). Similarly, since emigrating from World War II-era Europe in favor of the newly established Israel, Jews have been entrenched in a particularly intractable conflict with Palestinians over who belongs on what territory in the region (Bar-Tal, 1998; Kelman, 2003). This migration occurs in less extreme cases, too. In this chapter, I review evidence demonstrating how people with more orthodox, traditional, and conservative moral ideologies cluster into communities where most other residents are conservative while people with more modern, progressive, and liberal ideologies tend to cluster into communities where most other residents are liberal (Bishop, 2008; Bishop \& Cushing, 2008; Huckfeldt \& Sprague, 1995; McDonald, 2011; Motyl \& Iyer, 2013; Motyl \& Iyer, under review). Importantly, this clustering does not seem to be simply a result of social influence, but rather that people may be inspired to emigrate from places where they perceive that they do not fit and migrate to places where they perceive that they fit better.

\section{People Have an Intuitive Understanding of the Moral Values of Enclaves}

People don't need to check voting records to know the political flavor of a community. They can smell it.

- Bill Bishop, 2008, p. 23

At face value, people do not seem to have accurate, explicit knowledge of the ideological values endorsed in a given community. Rather, people tend to assume that others share their beliefs, and this in turn leads them to inaccurately perceive the attitudes and values of others (Hoch, 1987; Marks \& Miller, 1987; Ross, Greene, \& House, 1977). Some scholars even challenge people's knowledge of their own attitudes and preferences, suggesting that people may not even have the ability to describe their own positions (e.g., Nisbett \& Wilson, 1977; Wilson \& Dunn, 2004). This inability to introspect on one's own attitudes and to accurately assess others' attitudes makes the often-demonstrated attitudinal inconsistency and poor political knowledge among Americans unsurprising (Campbell, Converse, Miller, \& Stokes, 1961; Delli-Carpini \& Keeter, 1996, 2009; Gul \& Desendorfer, 2009). While this work on self-knowledge of one's attitudes paints a bleak picture for the prospect of selective migration into morally- and ideologically-fitting communities, some social psychological theories propose that people have intuitions, or gut-level pre-conscious emotional perceptions, that guide later thinking (Haidt, 
2001, 2002, 2007). The Ideological Enclavement Theory hypothesizes that people have an intuitive understanding of the moral values of small socio-ecological areas (e.g., neighborhoods), particularly by way of various cues in the social and physical environment.

Ambient belonging cues. One of the fundamental human motives is to belong and to be a valued member of social groups (Baumeister \& Leary, 1995; James, 1890; Leary, 2010; Maslow, 1968). This may be due to the benefits that belonging grants to those who have it. For example, belonging to supportive coalitions increases the likelihood of mating relationships and surviving despite existential threats (Wilson, 1990; Wilson \& Wilson, 2007; Kesebir, 2011; Tooby \& Cosmides, 1996). This evolutionary tale provides one explanation for why people readily form social groups, even in the most minimal of circumstances (e.g., randomly on the basis of eye color or dot-overestimation; Tajfel, Flament, Billig, \& Bundy, 1971). When there are numerous groups to which people may join, they will choose the groups that seem to bolster their relational value, provide them with better social exchange partners who may help them to best achieve their goals, and reinforce their self-concept and important values (McGregor, Nail, Marigold, \& Kang, 2005; Neuberg \& Cottrell, 2008; Neuberg, Smith, Hoffman, \& Russell, 1994; Pyszczynski et al., 2006).

To determine which groups may best confer these benefits, people evaluate characteristics ranging from explicitly social cues to more subtle environmental cues. Explicit social cues communicate belonging for majority group members and a lack of belonging for minority group members. For example, women participating in math, science, and engineering class video conferences reported feeling that they did not feel like they belonged in those fields when the cameras focused on a disproportionate number of men than women. Yet, when cameras depicted a more balanced ratio of women to men, these women perceived a greater sense of belonging (Murphy, Steele, \& Gross, 2007). Similarly, dark-skinned black students in majority white student schools reported that they felt like they did not belong at that school (see Lewis, 2012; Oyserman, Brickman, Bybee, \& Celious, 2006; and, Walton \& Cohen, 2011, for similar evidence in higher education). Thus, communities comprised of group members who physically resemble us may be especially alluring.

This similarity attraction effect robustly predicts who gets selected as social interaction partners (Byrne, 1971). Similarity in physical features may be such an important factor in who we choose to interact with because it may signal that the prospective interaction partners who look like us share similar genetics, may feel and think like us, and share our important values. And, surrounding ourselves with partners who share in our experiences, perceptions of reality, and possibly even a greater proportion of our genes is comforting (Alvarez, 2004; Buss, 1987; Byrne \& Clore, 1970; Hardin \& Higgins, 1996; Motyl et al., 2011; Swann, 1987). The fact that people are capable of predicting others' attitudes above chance from simply viewing a short video clip of them lends suggestive support for the idea that physical similarity conveys attitude similarity (see Ambady, Bernieri, \& Richeson, 2000; Borkenau, Mauer, Riemann, Spinath, \& Angleitner, 2004). In a direct test of this hypothesis, MacKinnon, Jordan, and Wilson (2011) found that participants viewed physically similar others as being attitudinally similar, too, even in the absence of attitudinal information. Furthermore, perceived attitude similarity mediated the effect of physical similarity on liking for that partner, and expectations that that partner would like and accept the participant. Additionally, recent surveys from Pew Research indicate that liberal and conservative Americans are drawn to very different types of communities ("Political Polarization in the American Public," 2014). Predictably, 77\% of liberal adults reported wanting to live in urban centers with high population density, compact homes (e.g., condominiums), 
walkable neighborhoods with extensive public transportation, cultural institutions like museums and theaters, and greater ethnic diversity. In contrast, conservative Americans wanted to live in more suburban or rural communities with low population density, larger single-family homes, good parking for their personally-owned vehicles, many religious institutions, and less ethnic diversity. Emily Badger, journalist at the Washington Post, concluded that "[this] is an enduring stereotype - conservatives prefer McMansions while liberals like urban enclaves - but one that is grounded in reality" ("Conservatives are from McMansions, liberals are from the city," 2014). These data are correlational, limiting the strength of the conclusions that can be drawn from them, but the convergence of data from multiple samples using multiple methods suggests that there are differences in the physical spaces within Blue America and Red America.

Ideological similarity, though, is typically more difficult to determine than physical similarity is. Thus, people need to use cues other than visible characteristics of potential interaction partners. It may be that attitudes, identities, ideologies, moral worldviews, and personalities are represented through ambient cues in the environment. If environments inhabited by people with different identities and personalities look different, observers may be capable of inferring the identities and personalities of the inhabitants (Gosling, Ko, Mannarelli, \& Morris, 2002). In an initial test of this hypothesis, Gosling and colleagues (2002) recruited participants to complete popular measures of personality characteristics and then sent a team of observers to assess the home and office environments of these participants. They found that not only did observers of these environments agree in their judgments about what different cues in these environments suggested about the inhabitants' personalities, but also that observers were remarkably accurate in predicting the participating inhabitants' personalities (especially in terms of extraversion, conscientiousness, and openness to experience). This perceptive capability permits people to determine where they would be more likely to find similar others who share their ideological values, who they seem to be seeking to satisfy their need to belong (Baumeister \& Leary, 1995). Specifically, the presence of cues in an environment that may be incongruent with people's identities may lead people to feel that they do not belong in that environment. In a series of experiments testing this possibility, Cheryan and colleagues (2009) found that computer science classrooms with identity cues of the computer science students, like the presence of Star Trek posters, video games, comic books, and soda cans, led women to feel that they did not belong in those classes and actually decreased women's interest in choosing to spend time in that environment. The presence of identity-incongruent cues, like the stereotypically-masculine computer science cues in this study, was more important in determining women's sense of belonging than was the number of other women in the classroom.

Perhaps, as suggested by Erving Goffman (1963), people's concerns about their identity are intricately linked with elements in the physical spaces they occupy. Some subtle environmental cues may convey more direct ideological and moral content. Companies signal their acceptance (or rejection) of minority group members through presence (or absence) of brochures and posters identifying "safe spaces" for members of diverse social groups. Communities signal their acceptance (or rejection) of adherents of different moral and religious worldviews through displays endorsing particular moral and religious codes. Regions signal their acceptance of different attitudes and values through their voting support for differing policy proposals affirming or condemning attitude objects and social behaviors. Indeed, black professionals felt that they did not belong and experienced heighte ned threat in companies that promoted a colorblind ideology through their diversity training programs (Purdie-Vaughns, Steele, Davies, Ditlmann, \& Crosby, 2008). Similarly, non-Christians reported a reduced sense 
of belonging when in the presence of Christmas decorations (i.e. signals of a welcoming environment for Christians; Schmitt, Davies, Hung, \& Wright, 2010). And, lesbian, gay, bisexual, transgender, and queer people felt like they belonged less in states with legislation banning same-sex marriage and in states with legislation that did not include sexual orientation among protected groups in hate crimes legislation (Lick, Tornello, Riskind, Schmidt, \& Patterson, 2012). Taken together, various ideological cues in the physical environment play a significant role in whether inhabitants of those environments feel like they belong.

Ideology and ambient cues. On its surface, ideology may seem to be a difficult characteristic on which to cluster, as ideologies are diverse and may not be on display very often (e.g., highly partisan elections occur only every 2 to 4 years, most religious holidays occur once a year, and other moral or ideological events occur even less frequently). Historically, this may have been true. However, throughout the late $20^{\text {th }}$ century and into the first decade of the $21^{\text {st }}$ century, the nature of mass politics has changed a great deal. In The American Voter, Campbell, Converse, Stokes, and Miller (1960; see also Converse, 1964) demonstrated that, according to nationally-representative National Election Study (NES) data from the previous decade, people were ideologically "innocent" and held views that did not consistently adhere to a particular ideology. One public opinion scholar joked that "public opinion appeared to be like butter on a grill - it just moves all over the place!" (personal communication, N. Winter). This volatility of public opinion seems to be shifting and people appear to be more ideological now than in United States history. Some debate this view by pointing to the decreasing membership in both major political parties and an increased tendency for people to describe themselves as "moderate" and identify as "political independents" (see Avlon, 2009). To some extent, people may be disidentifying with parties because they want to view themselves as independent and objective decision-makers (Hawkins \& Nosek, 2012), but this bears little relation to their partisan behavior. People may appear less partisan, but further examination suggests that these independents display the same political preferences as partisans on either side of the political aisle. Specifically, in two studies, Hawkins and Nosek (2012) demonstrate that people who implicitly identify with Democrats or Republicans or who admit to generally "leaning" toward preferring Democrats or "leaning" toward preferring Republicans are largely indistinguishable from traditional partisans in the original 7-point NES political identification question. In support of this, Bafumi and Shapiro (2009) argue that partisanship has returned and is more ideological than at any point in the last 30 years. Examining NES data over this time shows that, when accounting for people who say they are independent but "lean" toward one party or another, the number of pure independent voters is at its lowest level since the 1950s. In their analysis of General Social Survey (GSS) data, they find that Democrats and Republicans have diverged on most political issues. The sharpest divergences are on racial issues and tolerance of differences in moral issues such as abortion, same-sex marriage, and school prayer. Furthermore, Bafumi and Shapiro (2009) show that not only are partisans polarizing on these issues, positions on these issues are becoming increasingly related to religious, moral, and family values.

Today, the liberal vs. conservative "culture wars" imply that core values span most of a person's moral worldview, and that there are important differences between people who adhere to one worldview or another. Much in the same way that race is discussed, there are cultural and lifestyle differences between liberals and conservatives. Hunter (1991) argues that conservatives and Republicans prefer an "orthodox" lifestyle that is rooted in respect for authority and a tendency toward tradition. He argues that liberals and Democrats, on the other hand, prefer a "progressive" lifestyle that tends more toward challenging authority in pursuit of promoting 
human flourishing for all citizens equally. Hetherington and Weiler (2009) examined this hypothesis by looking at how traditional, non-political behaviors in one's life space predict their political behaviors in the broader social context. They found a very strong correlation between parents' belief in spanking their children as a necessary form of discipline and their support for President George W. Bush in the 2004 presidential election (Pearson's $r$ s ranged from .79 to .83 across two analyses). Numerous other scholars demonstrate a considerable correlation between moral and political identities (e.g., Abramowitz, 2012; Graham et al., 2009; Haidt \& Graham, 2007; Koleva et al., 2011; McAdams et al., 2008; Motyl, Iyer, \& Graham, 2015). Thus, ideology has expanded far beyond networks of political attitudes.

As ideological identities have expanded, now including attitudes toward affirmative action, taxes, war, and same-sex marriage, personality traits (e.g., openness to experience), church attendance, and parenting styles, they may be more visible in society. Indeed, people with liberal moral worldviews were significantly more likely to have varied books and music, art supplies, many books, international maps, movie tickets, and international cultural memorabilia in their bedrooms and office spaces than were people with more conservative moral worldviews (Carney, Jost, Gosling, \& Potter, 2008). People with conservative moral worldviews were significantly more likely to have sports-related décor, postage stamps, alcohol bottles, ironing boards, laundry baskets, and American flags in their bedrooms and office spaces than were people with more liberal moral worldviews. Organization and style of these spaces also differed between moral worldviews. Specifically, liberals tended to have darker, messier, more cluttered spaces whereas conservatives tended have cleaner, more brightly-lit, and less cluttered spaces (Carney et al., 2008). Thus, ideology may be considered a fundamental individual difference that bears a number of visible cues, making it easier for people to determine whether particular environments support particular moral worldviews and whether the inhabitants of those environments are morally similar (Motyl, Iyer, \& Graham, 2015).

Furthermore, communities with different moral worldviews also seem to lure different types of businesses and companies (Gimpel \& Karnes, 2007). Communities that tended to vote for Republican candidates had more than twice as many gun stores as bookstores. In contrast, communities that tended to vote for Democratic candidates had more than twice as many bookstores as gun stores. Upon delving further into these data, Gimpel and Karnes found that conservative communities had disproportionately more Wal-Marts and liberal communities had disproportionately more Whole Foods and Starbucks. Conservative communities preferred conservative talk radio to National Public Radio (NPR), and were populated with Evangelical and Mainline Protestant Churches. Liberal communities preferred NPR, and even Air America when available, to conservative talk radio and had a relative paucity of churches. Taken together, these findings lead to the stereotypic caricature painted by syndicated columnist Dave Barry (2008):

"As Americans, we must ask ourselves: Are we really so different? Must we stereotype those who disagree with us? Do we truly believe that ALL red-state residents are ignorant racist fascist knuckle-dragging NASCAR-obsessed cousinmarrying road-kill-eating tobacco-juice-dribbling gun-fondling religious fanatic rednecks; or that ALL blue-state residents are godless unpatriotic pierced-nose Volvo-driving France-loving left-wing Communist latte-sucking tofu-chomping holistic-wacko neurotic vegan weenie perverts?"

Of course, the answer is that Americans are not all of these things (or at least the vast majority of Americans, regardless of their political ilk, are not). However, the data reviewed 
above shed some light as to where these stereotypes emerge. Inhabitants of Red American communities do tend to like NASCAR and do tend to be religious. Inhabitants of Blue American communities do tend to like swanky coffee shops that serve lattes and do tend to prefer grocery stores that cater to vegan dietary preferences. These are the so-called grains of truth to the liberal and conservative stereotypes, but they are just that-grains of truth that vastly oversimplify to categories of people that describe most Americans.

In an initial examination of this hypothesis, Motyl and Iyer (under review) sought to determine whether individuals holding differing ideologies had preferences for distinct types of activities, characteristics, and stores. They found that liberals preferred communities with more bicycle paths, hybrid cars, universities, used bookstores, coffee shops, art walks, and organic markets. In contrast, conservatives preferred communities with more sport-utility vehicles, military bases, gun stores, professional football teams, and protestant churches. In follow-up studies, liberals and conservatives read descriptions of communities that included these subtle cues or more explicit cues of moral worldview (specifically, the percentage of people who are liberal or conservative). As predicted, participants did not differ in how they evaluated communities described with the subtle or explicit cues. Regardless of whether the ideological cues were explicit or subtle, participants reported that they preferred communities congruent with their own ideological values and that this tendency was linked to participants' perceptions that they would feel a greater sense of belonging in ideologically similar communities. This work provides further support for the Ideological Enclavement hypothesis that people are capable of inferring the ideological leanings of communities through the ambient cues of moral values present in the communities. Furthermore, the capability of inferring communities' values allows people to determine whether their personal moral values fit with the communities' moral values, and thereby, people may intuit where they could best satisfy their need to belong.

\section{Intuitions Steer Selective Migration into Ideological Enclaves}

Human groups have long migrated as they have sought to satisfy their basic human needs. Early humans emigrated from Africa seeking access to food and water, protection from the extreme climatic elements, safety from competing, hostile groups of other humans, and in search of social connections (Boyd \& Richerson, 2005; Kenrick et al., 2010; Van de Vliert, in press). Modern humans migrate for these reasons, but for many others, too. People consider the activities differe nt residences would permit, the proximity to (or distance from) family members, the availability of desirable occupations, and whether they would feel a sense of belonging in those communities (Motyl, 2014; Motyl, Iyer, Oishi, Trawalter, \& Nosek, 2014). It is this pursuit of belonging that may lead to the emergence of increasingly ideologically- and morally-homogeneous enclaves.

Migration and mobility. Roughly half of the American population changed their residence between 1995 and 2000 (Schmitt, 2001), and an estimated 40-50 million Americans move each year (Florida, 2008). Understanding how people make these residential migration decisions is complex (Greenwood, 1985; Oishi, 2010). Employment, family, finances, personality, and temperament all influence migration (Jokela, 2009; Jokela, Elovainio, Kivimaki, \& Keltikangas-Jarvinen, 2008; Winstanley, Thorns, \& Perkins, 2002). People likely make these decisions in ways that help them pursue their goals. For example, experts in particular occupations tend to move to communities seeking such specialists (Florida, 2004), and extroverts may move to communities with more socially-stimulating environments (Furnham, 1981). In these cases, the migrants may be assuming that the residents living in their destination communities are similar. Indeed, actual residential mobility and even contemplating migrating 
increases people's familiarity-seeking behavior (Oishi, Miao, Koo, Kisling, \& Ratliff, 2011). As discussed above, ideological and moral similarity appears to be more appealing than mere surface-level similarity (see also Haidt, Rosenberg, \& Hom, 2003). So, an influence on migration may be seeking environments populated by ideologically-similar others (Byrne, Clore, \& Smeaton, 1986; Karylowski, 1976; Werner \& Parmelee, 1979).

A complementary possibility is that people migrate away from communities based on feeling repulsed by the preponderance of dissimilar others (Rosenbaum, 1986). People may migrate when they feel they do not belong in their current community. In some cases, people may find the moral values of their current community disgusting, or threatening to their worldview, eliciting unpleasant existential anxiety (Haidt \& Graham, 2007; Motyl, Vail, \& Pyszczynski, 2009; Schimel, Hayes, Williams, \& Jahrig, 2007). This identity-related, threatinduced migration seems to play a role in the segregation of ideological and religious groups around the world, including Serbians, Croatians, Muslims, Jews, Albanians, Hindus, Sikhs, Buddhists, and Christians (Lim, Metzler, \& Bar-Yam, 2007). It stands to reason that this could also play a role in the ideological segregation of Red America and Blue America. When evaluating residential options, people may be especially likely to move away from communities with values that are ideologically incongruent.

The Ideological Migration Hypothesis. Regardless of whether people are generally being attracted to or repulsed from different communities, it is clear that people desire communities where they share ideological values with their neighbors and are connected to each other in their ideological identity. Cultures lacking sufficient social integration displayed higher suicide rates than those with sufficient social integration (Durkheim, 1893, 1897). More recently, cross-cultural sociological research demonstrates that in 68 different countries greater social integration predicted reduced suicide rates (Lenzi, Colucci, \& Minas, 2012). In the United States, the suicide rate for liberals living in conservative communities that preferred Senator John McCain, and for conservatives living in liberal communities that supported President Barack Obama, were both higher than the rate for liberals living in communities that supported President Obama and conservatives living in communities that supported Senator McCain in the months after the 2008 Presidential election (Classen \& Dunn, 2010). In other words, people with ideologies incongruent with the ideology of the communities in which they lived exhibited heightened suicide rates relative to the people with ideologies that were more congruent the ideologies of the communities in which they lived. Luckily, though, there are less drastic solutions to resolve a lack of ideological fit between person and community; people can pack up and move.

Herein lies the Ideological Enclavement Theory's ideological migration hypothesis. When people perceive that their ideological values do not fit in their current community, they perceive that they do not belong and are increasingly likely to migrate to a new, more ideologically-fitting community. Community-level, sociological data provide support for this hypothesis, suggesting that people are migrating away from ideologically misfitting communities and toward ideologically-fitting ones (Bishop, 2009; Bishop \& Cushing, 2008). These aggregatelevel data, though, do not clarify the psychological processes contributing to migration. The correlational, aggregate community data do not, for example, address the possibility that the ideology of the majority group in a given community are gradually adopted by the minority group through social influence (Asch, 1956; Cialdini \& Goldstein, 2004; Festinger, 1963; Harton, \& Bullock, 2007; Latane, 1981; Sinclair, Lowery, Hardin, \& Colangelo, 2005). 
In an individual-level test of this hypothesis, Motyl and colleagues (2014) found that people do indeed seek communities with ideological values that fit with their own. In Study 1, we found correlational evidence in a large, national sample suggesting that people who lived in communities where their ideologies were misfit were more likely to have migrated in the past, and when those people migrated, they selected communities more congruent with their own personal ideologies. In Study 2, we found more correlational evidence in a different national sample, showing that participants were able to accurately identify the ideological values of communities (possibly by intuiting fit vs. misfit via a community's ambient cues of ideology). Perceiving the ideologies of the communities in which they resided as misfit with their own ideologies decreased their sense of belonging and engendered an increased desire to migrate to a different community. Importantly, sense of belonging fully mediated the relationship between ideological fit and migration desire, suggesting that the mediating psychological mechanism may, in fact, be sense of belonging. In Study 3, we experimentally manipulated participants' perceptions of community ideologies and found that when participants thought that their community was becoming more ideologically incongruent, participants expressed a decreased sense of belonging and an increased desire to migrate to a new community. Similarly, Americans who voted for Governor Romney in his bid for the U.S. Presidency expressed a greater willingness to emigrate from the United States on the day following Governor Romney's electoral loss to President Obama, as they perceived the nation to be growing increasingly liberal and at odds with their conservative moral values (Motyl, 2014). These findings lend support for Ideological Enclavement Theory's ideological migration hypothesis, suggesting that ideological fit affects migration tendencies, and that the relationship is driven by people's desire to satisfy their belonging needs. Furthermore, ideological migration leads to the emergence of ideological enclaves with ever-increasing homogeneity in their ideologies.

Living in ideologically-homogeneous communities has numerous consequences for individuals, their interactions with other individuals, intragroup functioning, and intergroup relations. I turn now to a detailed discussion of these consequences.

\section{Ideological Enclaves Promote Intrapersonal, Interpersonal, and Intragroup Thriving}

This tendency to migrate into increasingly ideologically-homogeneous communities may have a number of positive consequences. Individuals migrate to homogeneous enclaves to increase their sense of belonging with their communities. Having a strong sense of belonging has many positive psychological consequences such as improved academic performance, reduced mental and physical health problems, and subjective well-being (Haslam, Jetten, Postmes, \& Haslam, 2008; Leary, 2009; Major \& O'Brien, 2005; Sheldon \& Bettencourt, 2010; Walton \& Cohen, 2011). Further, ideological homogeneity may reduce daily interpersonal conflict with dissimilar others. Indeed, among types of diversity, ideological moral diversity is very unpopular (Haidt, Rosenberg, \& Hom, 2003). Without fear of reprisal for expressing one's values, one may be able to more easily form strong interpersonal bonds and accumulate social capital (see Coleman, 1988; Putnam, 2000).

With better social bonds and increased social capital, people may more easily flourish. When people feel like their values matches their environment, they experience greater subjective well-being and increased self-esteem (Fulmer et al., 2010). In turn, heightened subjective wellbeing promotes longevity, reduces bad cholesterol and blood pressure, and expedites recovery from negative emotional experiences (Danner, Snowdon, \& Friesen, 2001; Fredrickson, 2000; Fredrickson \& Joiner, 2002; Fredrickson \& Levenson, 1998; see Lyubomirsky, King, \& Diener, 
2005 for a review). People may even be reducing the suicide rate by migrating into these enclaves where they are buffered from moral despair and "social disintegration" (Classen \& Dunn, 2010; Durkheim, 1893).

Within-group functioning may also be enhanced by ideologically-homogeneous communities. For example, increasing a sense of belonging among marginalized groups can increase academic achievement (Schmitt, Oswald, Friede, Imus, \& Merritt, 2008; Walton \& Cohen, 2007). Similarly, work teams composed of employees with similar values outperformed works teams composed of employees with diverse values (Baugh \& Graen, 1997; Ely \& Thomas, 2001; Hartel \& Fujimoto, 1999; Guillaume, Brodbeck, \& Riketta, 2012; Phillips \& Lloyd, 2006; van Knippenberg \& Schippers, 2007). And, employees prefer working in teams comprised of individuals with similar values, more so than teams comprised of individuals with similar demographic characteristics (Hobman, Bordia, \& Gallois, 2003; Jackson et al., 1991; Jehn, Chadwick, \& Thatcher, 1997; Pelled, 1996).

Political scientists have demonstrated that ideological diversity in people's social networks can lead to disengagement from politics. For example, Huckfeldt, Mendez, and Osborn (2004) suggest that ideological heterogeneity within one's social network decreases voter turnout. Similarly, McClurg (2006) suggests that the partisan composition of one's neighborhood context determines mobilization. Specifically, conversations with people who disagree with a citizen have unique effects contingent upon whether that person is in the minority or majority in that neighborhood. If that citizen is in the majority, experiencing disagreement within the social context will have no discernible effect on their tendency to vote. However, if that citizen is in the minority, experiencing disagreement within the social context will reduce their person's tendency to vote. In other words, liberals living in Red America and conservatives living in Blue America may participate in the political process less. This reduced participation may further accentuate the perception of communities being more liberal or more conservative than they actually are. Thus, ideologically-homogeneous communities may be positive for their ideologically-fit citizens (although, negative for the ideologically-misfit citizens).

\section{Ideological Enclaves Foster Intergroup Despising}

The emergence of ideological enclaves leads to the segregation of liberals and conservatives into Blue and Red America, respectively. Voluminous past research demonstrates that a lack of positive contact between members of different groups leads to increased intergroup conflict (for a review, see Pettigrew \& Tropp, 2006).

Bias. This environmental segregation has profound psychological effects, which operate to further environmental segregation and catalyze political change. In classic social psychological research, researchers invited a group of kids to attend a summer camp (Sherif et al., 1961). These kids were selected based on how psychologically "normal" they were. After being selected, the researchers randomly assigned them to one of two groups who would reside in two separate camps that were segregated from one another in Robber's Cave National Park in Oklahoma. When these two arbitrarily-determined groups became aware of each other's existence, conflict ensued. When these two groups participated in competitive games of baseball or tug-of-war, they became viciously hostile towards one another. On several occasions camp counselors had to break up fights occurring between members of each of these groups. More recent social psychological research has shown that people demonstrate in- and out-group bias even when they are arbitrarily assigned to groups based on their purported performance on mundane visual perception task (even though their feedback was determined before they 
participated to ensure true random assignment to groups; see Tajel, 1970). Tajfel showed that the mere categorization of people into groups, even without any real distinctions between the groups can foster group bias. When groups are more meaningful and are of great importance to their members, group bias becomes even more extreme (Motyl \& Pyszczynski, 2010; Pyszczynski, Motyl, \& Abdollahi, 2010). Liberals and conservatives do not simply show a positive bias toward their own groups, but also an intense hatred for the other side (Crawford, Modri, \& Motyl, 2013).

Polarization and extremitization. Real groups that correspond with a set of values and principles can foster much more intense group polarization and engender hostility against outgroup members. Generally, groups tend to become increasingly extreme in their attitudes the more they communicate with likeminded others and avoid encountering alternative viewpoints. For example, Sunstein (2009) reports a set of studies in which he examined groups of people he expected to be impartial and objective-Federal Judges. He categorized judges based on whether they were Democratically- or Republican-appointed. These judges sat on panels consisting of three members that had four possible combinations, all Democratic-appointed, all Republicanappointed, two-Republican appointed and one Democratic-appointed, or two-Democraticappointed and one Republican-appointed. Therefore, this polarization hypothesis could be tested by comparing the tendency of homogeneous groups of judges on their rulings on social issues cases to each other and to the heterogeneous groups of judges. Sunstein found that on gay rights cases, all Republican-appointed judges voted in favor of gay rights $16 \%$ of the time whereas Democratic-appointed judges voted in favor of gay rights $57 \%$ of the time. However, when Republican-appointed judges sat on homogeneous panels voted in favor of the gay rights' plaintiff $14 \%$ of the time whereas when the Democratic-appointed judges sat on homogeneous panels they voted in favor of gay rights $100 \%$ of the time. This basic pattern of effects held across a series of other issues ranging from support for affirmative action to redressing sex discrimination. These findings suggest that when people are in a homogeneous group where they are surrounded by others who corroborate their beliefs, they tend to become more radical in their beliefs. In some extreme cases, this cycle of increasing animosity more precipitate political violence (Motyl \& Pyszczynski, 2010; Motyl, Rothschild, \& Pyszczynski, 2009; Motyl, Vail, \& Pyszczynski, 2009; Pyszczynski, Motyl, \& Abdollahi, 2009; Pyszczynski, Vail, \& Motyl, 2009; Vail, Motyl, Abdollahi, \& Pyszczynski, 2009). Thus, as these ideological enclaves emerge and the inhabitants have less contact with people holding different values, the inhabitants will be increasingly likely to polarize and become more extreme in their beliefs.

Naïve realism. People tend to think that they view the world objectively and that everyone else makes judgments based on this same "objective" reality (Keltner \& Robinson, 1996). Every person, based on myriad factors, perceives the world in different ways. There are differences in people's auditory, olfactory, and visual sensory abilities. There are differences in the experiences people accumulate over time. In cases where people live in geographically distinct locations and are given specific biased information about the world, this discrepancy in our own perceived objectivity and our perception that others see the world as we do is problematic. Keltner and Robinson (1996) argue that people tend to assume that when others disagree on a matter of "objective" truth, they are doing so out of ideological bias which prevents them from seeing the objective truth. Inherent in this notion of naive realism is that the perceivers, no matter how biased they may actually be, perceive themselves to be objective and more moderate than those who disagree with them. 
Motivated reasoning and extremist attitudes. This process requires some degree of mental gymnastics, but the human mind is gifted with the incredible powers of motivated reasoning. This motivated reasoning allows people seek out confirmation of whatever they want to believe and disconfirmation of that which they do not want to believe (Kunda, 1990). In cases where people encounter information that fits with their understanding of the world, they ask, "Can I believe this?" The answer is almost always "yes." Alternately, where people encounter information that challenges their understanding of the world, they ask, "Must I believe this?" The answer is almost always "no." Consider, for example, the suggestion that President Barack Obama is the anti-Christ. If you believe that he is, you will likely cite passages from religious texts and possibly mention the end times. If you do not believe that he is, you will likely assume that people who make such claims should report to their nearest mental hospital. There is, however, an important disjoint here that seems to characterize much of modern-day American politics. People have a belief that skirts any hope of deliberation and makes the quick assumption that anyone who disagrees with you must be mentally imbalanced (Kosloff, Greenberg, Schmader, Dechesne, \& Weise, 2010; Pyszczynski, Henthorn, Motyl, \& Gerow, 2010). Consider, for another example, the view of conservative political talk radio show host Michael Savage (2005) who argues that liberalism is a mental disorder. His view is that one must be mentally ill to support liberal immigration, national security, and economic policies. However, liberals often characterize him (and many of his conservative pundit brethren) as "moonbats" or "wingnuts" (Avlon, 2009; Franken, 2006). These motivated conclusions do not facilitate political conversations or deliberations moving a people ever closer to political solutions. Rather, these processes escalate conflict between groups who live in very different Red- and Blue-colored worlds.

Implicit misunderstanding. These distinct understandings of the world create "mindblindness" and "moral empathy gaps" where they "just can't get" people who hold views discrepant from their own (Ditto \& Koleva, 2011). This mental block preventing people from understanding the merit of others' beliefs and how others' can be good, moral beings even if they do not share in our ideological worldview enhances political conflict. This recognition of others' moral intuitions is difficult because intuitions are often ineffable. In this respect, moral intuitions are similar to implicit cognitions. Implicit political cognition and moral intuitions represent hardto-describe (if at all possible) gut-level reactions to one's world. These gut-level reactions emerge from a confluence of forces ranging from genetics, socialization, and one's present environment (Alford, Funk, \& Hibbing, 2005; Huckfeldt, Johnson, \& Sprague, 2002; Sears, 1975). These implicit cognitions sometimes diverge from what people explicitly say they believe and implicit cognitions appear to be slower to change, perhaps because they are more resistant to socially-desirable responding and more likely to represent one's automatic evaluation of a party, person, or policy based on their past and current experiences. Recent research suggests that these implicit cognitions and intuitions may be better predictors of subsequent political behaviors, including voting choice, than explicit self-reported attitudes are (Arcuri, Castelli, Galdi, Zogmaister, \& Amadori, 2008; Friese, Bluemke, \& Wanke, 2008). While the field of implicit political cognition is still in its toddlerhood (Stone, Johnson, Meindl, Beall, Smith, \& Graham, 2014), it should be considered in any comprehensive analysis of intergroup relations, and interventions should be considered that reduce implicit biases, in addition to explicit biases.

\section{Comparing and Contrasting Theories}

Social psychological research has long emphasized the importance of the situation on the individual (e.g., Bronfrenbrenner, 1977; Cohen \& Leung, 2010; Lewin, 1951). Examples of 
social influence effects in the laboratory and in everyday life are numerous. In laboratory studies, participants adopt the public attitude of those around them on non-moral issues, such as the movement of a dot or the length of a line (Asch, 1951; Sherif, 1936). In other settings, descriptive and injunctive norms may lead participants to behave in ways consistent with what others in those settings are doing. For example, people recycle more when the social norm is to recycle (Cialdini, Kallgren, \& Reno, 1991). In some cases, people will socially "tune" their attitudes to be more amenable to the expected attitudes held by future interaction partners (Lowery, Hardin, \& Sinclair, 2001). Broader theories (e.g., Dynamic Social Impact Theory; DSIT, hereafter) argue that culture is created in a bottom-up fashion and that attitudes within a given culture emerge through communication with others in that culture (Harton \& Bullock, 2007; Latane, 2006; Nowak, Szamrej, \& Latane, 1990). Together, this tradition of research has been informative showing how malleable attitudes and behaviors are.

Much of this thinking, though, stems from a time when societies were less residentially mobile. As societies have become more mobile, people have greater flexibility to choose different environments (Oishi, 2010). People seem to choose communities, in part, based on how similar they perceive the values of those communities to be to their own personal moral values (Bishop \& Cushing, 2008; MacDonald, 2011; Motyl, 2014; Motyl et al., 2014). This is not to say that people's attitudes are resistant to change once they select a community to inhabit, but it does add a top-down component to the dynamic social impact perspective. DSIT claims, "if everyone around you loves sweet tea and keeps offering it to you, you may come to try it and like it yourself" (Harton \& Bullock, 2007, p. 523). This claim is very plausible. However, it seems unlikely that if everyone around you loves intelligent design in biology classrooms and they keep offering to include it in your local public school's curriculum, you are probably not likely to change your pre-existing conviction that intelligent design has no place in a biology classroom. Indeed, when it comes to sacred values and moral convictions, people are less likely to change their position on these issues (see Bauman \& Skitka, 2009; Haidt \& Hersh, 2001; Skitka, Bauman, \& Sargis, 2005; Taber \& Lodge, 2006; Tetlock, Kristel, Elson, Lerner, \& Green, 2000). Rather, people respond to counterattitudinal arguments in these contexts with a more critical eye, seeking all the reasons why the counterargument to their own position is incorrect (Ditto \& Lopez, 1992; Kunda, 1990). In some cases, information that counters one's own ideological values elicits anxiety and strong emotional reactions which affects later behavior and judgments of others (Haidt, 2001; Schimel et al., 2007). These affective and motivated cognitive reactions are not likely to result in attitude change (Petty \& Krosnick, 1995). Rather, people may resist social influence and polarize as they become more entrenched in their pre-existing attitudinal positions (Lord, Ross, \& Lepper, 1979; Munro \& Ditto, 1997). Thus, Ideological Enclavement Theory proposes that one way people respond to disagreement in their community is by disengaging and potentially migrating to a different community where there is more agreement on ideological issues.

\section{Future Directions}

Ideological Enclavement Theory seeks to understand the cleavages between ideological groups is supported by voluminous past research, but requires more direct tests of its specific claims. This theoretical approach claims that people intuit belonging from subtly ideological cues in their environments. Indirect evidence (e.g., Cheryan et al., 2009) and preliminary research (e.g., Motyl \& Iyer, under review) support this idea, but more direct tests are necessary. Specifically, the theory predicts that people would be able to infer the values of different 
locations in communities as a result of the cues in those locations. This work has yet to be conducted.

Ideological Enclavement Theory incorporates research from diverse communities within the social sciences demonstrating the consequences of belonging, having person-organization match, or culture-person congruence on individuals, the groups individuals belong to, and the relationships between different groups (e.g., Gelfand et al., in press; Hobman, Bordia, \& Gallois, 2003; Leary, 2010). For the most part, ideological fit has relatively more positive consequences for individuals and the groups they belong to and relatively more negative consequences for intergroup relations. This trade-off is worrisome. Future research should examine ways to capture the positive effects of moral fit for the individual without the negative effects of moral fit for intergroup relations.

Thriving, but not despising? Ingroup love and outgroup hate are distinct constructs (Brewer, 1999; Halevy, Bornstein, \& Sagiv, 2008; Waytz, Young, \& Ginges, 2014). The separateness provides the encouraging possibility that interventions promoting one do not necessarily harm the other. Rather, it may be possible to promote ingroup love without also promoting intergroup hatred. Past research provides some possibilities to promote individual, within-group thriving, and between-group thriving.

Shared humanity and shared values. In intergroup conflicts, particularly when the groups hold differing moral worldviews, members of each group tend to view each other as qualitatively different in essence, and often as evil, ignorant, incompetent, and insane (Kruglanski \& Fishman, 2006; Motyl et al., 2009; Motyl \& Ditto, in prep; Pyszczynski, Motyl, \& Abdollahi, 2009). Thus, promoting a sense that outgroup members share basic human characteristics and desires may lead to improved intergroup relations, without any negative consequences for the individual. In a series of studies, Motyl, Hart, and colleagues (2011) demonstrated that eliciting a sense shared humanity through depicting basic human activities (like eating dinner with one's family) or asking people to reflect on positive or negative childhood experiences led to reduced implicit hostility against Arabs, reduced support for war, and increased support for using peaceful diplomatic means in resolving international disputes. Furthermore, these effects were mediated by the sense that members of outgroups had shared experiences and were similar to ingroup members in simple, human ways. These findings are encouraging, although rely on making salient to individuals ways in which outgroup members may be similar to them and this intervention may be particularly short-lived.

Superordinate identities and threats. Shared goals promote intergroup cooperation and intergroup relations more generally (Sherif, 1958; Sherif et al., 1961). While goals of people holding different moral worldviews may often differ, there are some threats that face all people in a particular country or everywhere around the world. For example, in the wake of the terrorist attacks of September 11, 2001, liberals and conservatives in the United States set aside their hostility towards one another and identified more strongly with the more inclusive, superordinate group of being "Americans" (see Pyszczynski, Greenberg, \& Solomon, 2003). This temporary rise in the endorsement of the American identity resulted in increased church attendance, support or their president, and dramatic increases in pro-social behaviors like donating blood and volunteering for food kitchens (Landau et al., 2004). These activities appear to be especially important predictors of social integration and suicide rate (Lenzi et al., 2012). While these effects were short-lived, countries mired in intractable conflicts show similar effects. Israel provides one instance of prolonged cooperation between their left-wing and right-wing coalitions and broader societal integration, possibly as a result of continued superordinate threat from attack (Castano, 
2004). In each of these examples, another social group poses the threat that fosters a more superordinate identity within country and one could argue that this is not promoting improved intergroup relations (at a higher level of analysis, between country as opposed to within country). However, people face numerous threats from non-human groups. Global climate change, for example, could have profound implications for people regardless of their national identity. Pyszczynski, Motyl, Hirschberger, Vail, and Kesebir (2012) demonstrated that prompting people to consider the potential negative consequences of global warming led to improved intergroup relations in terms of support for using extreme military tactics, support for war, support for peace-making and diplomacy, and support for the use of terrorist attacks. Importantly, this effect was not limited to American college students. Rather, this effect was shown for liberals and conservatives in the United States and replicated in Israel and Palestine on non-student populations during the 2009 bombings, and in Iran among fundamentalist Muslims. These studies provide support for the gloomy prospect of promoting individual, within-group, and between group thriving without exacerbating human relations at a different level of analysis. Moreover, given the intensity of the conflict between the groups examined in the aforementioned studies, it seems more likely that emphasizing superordinate identities and superordinate threats will be effective in relatively less intense conflicts, like that seen in the American culture wars.

Cross-group contact and friendships. Under certain conditions, members of different groups may view each other more positively if they have more contact with one another (Allport, 1954; Pettigrew \& Tropp, 2006). This approach has been adopted by various groups around the world in attempts to improve intergroup relations. For example, organizations like Children of Abraham in Israel foster summer camps where Israeli and Palestinian children come together and get to know one another in a non-threatening environment and may lay the groundwork for cross-nationality friendships. Similarly, groups like To The Village Square sponsor regular dinners and events bringing together American liberals and conservatives to promote more civil dialogue between them. The actual effectiveness of these interventions has not yet been demonstrated, but conceptually they should improve intergroup relations without any negative consequences for individuals or within-group functioning.

Intergroup friendships are not especially common. In the United States, people's own political ideology is an excellent predictor of their friends' political ideology (Poteat, Mereish, Liu, \& Nam, 2011). Most people had some ideological heterogeneity within their social network, but substantial ideological segregation existed. Research on Australian participants suggests that selecting ideologically similar social interaction partners is driven by a fear of rejection from people with discrepant ideological values (Barlow, Louis, \& Hewstone, 2009). Analogously, people tend to overestimate the likelihood that they would not get along with members of other groups and that this may lead to more stressful interactions and reduce the desirability of having these intergroup interactions (Mallett, Wilson, \& Gilbert, 2008; Trawalter, Richeson, \& Shelton, 2009). Importantly, though, among participants who do have positive contact with outgroup members, attitudes toward that outgroup were more positive (Mallett et al., 2008; Poteat et al., 2011). Given the anticipated discomfort, fostering these positive contact situations may be difficult. Some educators propose that classes on dialogue at universities may serve as a good platform, as students with diverse backgrounds could be required to participate. In one qualitative study of this type of course at the University of Illinois, it appears that these courses seem to have some positive effects for intergroup relations - particularly, in helping people with divergent beliefs come to understand each other's beliefs (Hess, Rynczak, Minarik, \& LandrumBrown, 2010). In more rigorous quantitative work, people who are randomly assigned to make 
friends who belong to different racial and ethnic groups display decreases in stress, as indexed by cortisol reactivity in intergroup interactions (Page-Gould, Mendoza-Denton, \& Tropp, 2008). Given that stress associated with intergroup interactions is linked with fear of rejection (Barlow et al., 2009), buffering people's sense of self-integrity may also reduce the anxiety-induced intergroup interaction discomfort. Indeed, partisans who affirmed their self-concept in the days before the 2008 US Presidential election were less partisan in their evaluation of the other party's candidate's debate performance, were more positive towards the opposition candidate, and more willing to consider alternative perspectives (Binning, Sherman, Cohen, \& Heitland, 2010). Thus, affirming people's self-concepts and buffering them from their fear of rejection may increase the likelihood of people from different groups choosing to interact with each other, and to interact in ways that have positive, longer-lasting consequences.

This list of prospective interventions is not exhaustive, but includes three broad categories of techniques that are relevant to identity and belonging concerns embedded in Ideological Enclavement Theory. Humanization of outgroup members, recategorization of group boundaries to be more inclusive, and the formation of positive relationships with members of other groups all improve intergroup relations, and none of them seem to do so at the expense of the individual.

\section{Conclusion}

It is well-documented that people are drawn toward similar others and that they tend to cluster with people similar to them. Most research on this subject has focused on racial homophily and racial segregation, with little attention given to important identity-related concerns, to potential psychological mechanisms driving this tendency, and the potential consequences of this process that leads to the emergence of homogeneous and segregated communities. The process of Ideological Enclavement described in this chapter provides a theoretical framework to better understand how this process works and what the different consequences may be. Specifically, this approach proposes that people intuit a sense of belonging in different physical spaces. Absent explicit knowledge of the values held by people in different physical spaces, people may use subtle cues to determine whether they would belong there or not. Sometimes these cues may be surface-level, demographic characteristics, which provides some understanding of the emergence of racially segregated communities. Other times, these cues may be deeper-level cues that are implicitly linked with moral values, like the proportion of hybrid cars to sport-utility vehicles in a community, which provides further understanding of the emergence of ideologically segregated communities. Then, Ideological Enclavement Theory proposes that people are incited to migrate when they intuit that they do not belong in their community, and when they migrate, they migrate to communities where they intuit a greater sense of belonging. This theory then proposes three categories of consequences. First, living in ideologically-fitting communities promotes individual happiness, health, and well-being. Second, living in ideologically-homogeneous enclaves promotes social capital, social integration, and within-group cooperation. Third, the ideologically-segregated enclaves give way to increasingly hostile interactions between groups living in other ideological and moral enclaves with discrepant ideological and moral values. This theoretical approach brings to life and gives broader meaning to Frazier's claim that the "spatial pattern of the community is the basis of a moral order" (1962, p. 613). 


\section{References}

Allport, G. W. (1954/1979). The nature of prejudice. Reading, MA: Addison-Wesley.

Anderson, M. R. (2009). Beyond membership: A sense of community and political behavior. Political Behavior, 31, 603-627.

Asch, S. E. (1951). Effects of group pressure upon the modification and distortion of judgments. Groups, leadership, and men, 222-236.

Avlon, J. (2010). Wingnuts: How the lunatic fringe is hijacking America. New York, NY: Beast Books.

Bandura, A. (1999). Moral disengagement in the perpetration of inhumanities. Personality and Social Psychology Review, 3, 193-209.

Barlow, F. K., Louis, W. R., \& Hewstone, M. (2009). Rejected! Cognitions of rejection and intergroup anxiety as mediators of the impact of cross-group friendship on prejudice. British Journal of Social Psychology, 48, 389-405.

Baugh, S. G., \& Graen, G. B. (1997). Effects of team gender and racial composition on perceptions of team performance in cross-functional teams. Group \& Organization Management, 22, 366-383.

Bauman, C. W., \& Skitka, L. J. (2009). In the mind of the perceiver: Psychological implications of moral conviction. In D. Bartels, C. W. Bauman, L. J. Skitka, \& D. Medin (Eds.) Moral Judgment and decision making: Psychology of learning and motivation (pp. 341-364). San Diego, CA: Academic Press.

Baumeister, R. F., \& Leary, M. R. (1995). The need to belong: Desire for interpersonal attachments as a fundamental human motivation. Psychological Bulletin, 117, 497-529.

Binning, K., R., Sherman, D. K., Cohen, G. L., \& Heitland, K. (2010). Seeing the other side: Reducing political partisanship via self-affirmation in the 2008 presidential election. Analyses of Social Issues and Public Policy, XX, XX-XXX.

Bishop, B. (2009). The big sort: Why the clustering of like-minded America is tearing us apart. Boston, MA: Houghton-Mifflin Harcourt.

Brehm, J. (1956). Post-decision changes in desirability of alternatives. Journal of Abnormal and Social Psychology, 52, 384-389.

Bronfenbrenner, U. (1977). Toward an experimental ecology of human development. American psychologist, 32(7), 513.

Bushman, R. L. (2005). Joseph Smith: Rough stone rolling. New York, NY: Alfred A. Knopf.

Byrne, D., Clore, G. L., \& Smeaton, G. (1986). The attraction hypothesis: Do similar attitudes affect anything? Journal of Personality and Social Psychology, 51, 1167-1170. doi: 10.1037/0022-3514.51.6.1167

Campbell, A., Converse, P., Miller, W. E., \& Stokes, D. E. (1960). The American voter. New York: John Wiley \& Sons, Inc.

Carney, D. R., Jost, J. T., Gosling, S. D., \& Potter, J. (2008). The secret lives of liberals and conservatives: Personality profiles, interaction styles, and the things they leave behind. Political Psychology, 29, 807-840.

Cheryan, S., Plaut, V. C., Davies, P. G., \& Steele, C. M. (2009). Ambient belonging: How stereotypical cues impact gender participation in computer science. Journal of Personality and Social Psychology, 97, 1045-1060.

Chinni, D., \& Gimpel, J. (2010). Our patchwork nation: The surprising truth about the "real" America. The 12 community types that make up our nation. New York, NY: Gotham Books. 
Classen, T. J., \& Dunn, R. A. (2010). The politics of hope and despair: The effect of presidential election outcomes on suicide rates. Social Science Quarterly, 91, 593-612.

DOI: $10.1111 /$ j.1540-6237.2010.00709.x

Cohen, D., \& Leung, A. K. Y. (2010). A CuPS (Culture X Person X Situation) perspective on violence and character. Human aggression and violence: Causes, manifestations, and consequences. Washington, DC: American Psychological Association.

"Conservatives are from McMansions, liberals are from the city" (2014, June 12). Washington Post. Retrieved 9/1/2014 from http://www.washingtonpost.com/blogs/wonkblog/wp/2014/06/12/your-house-says-anawful-lot-about-your-politic s/?tid=sm_fb

Converse, P. E. (1964). The nature of belief systems in the mass Public. In David Apter, (ed.) Ideology and Discontent. New York: Free Press.

Craik, K. H. (2000). The lived day of an individual: A person-environment perspective. In W. W. Bruce, K. H. Craik, \& R. H. Price (Eds.), Person-environment psychology: New directions and perspectives (2nd ed., pp. 233-266). Mahwah, NJ: Lawrence Erlbaum Associates Publishers.

Crawford, J. T., Modri, S., \& Motyl, M. (2013). Bleeding-heart liberals and hard-hearted conservatives: Subtle political dehumanization through differential attributions of human nature and human uniqueness traits. Journal of Social and Political Psychology.

Ditto, P. H., \& Koleva, S. P. (2011). Moral empathy gaps and the American culture war. Emotion Review, 3, 331-332. doi: 10.1177/1754073911402393

Ditto, P. H., \& Lopez, D. F. (1992). Motivated skepticism: Use of differential decision criteria for preferred and nonpreferred conclusions. Journal of Personality and Social Psychology, 63, 568-584.

Elfenbein, H. A., \& O'Reilly, C. A. (2007). Fitting in: The effects of relational demography and person-culture fit on group process and performance. Group \& Organization Management, 32, 109-142.

Ely, R. J., \& Thomas, D. A. (2001). Cultural diversity at work: The effects of diversity perspectives on work group processes and outcomes. Administration Science Quarterly, 46, 229-273.

Fischer, C. S., \& Mattson, G. (2009). Is America fragmenting? Annual Review of Sociology, 35, 435-455.

Florida, R. (2008). Who's your city? How the creative economy is making where to live the most important decision of your life. Basic Books: New York, NY.

Frazier, E. F. (1962). Desegregation as an object of sociological study. In A. M. Rose (ed.), Human behavior and social processes (pp. 608-624). London, UK: Routledge.

Gilens, M. (2001). Political ignorance and collective policy preferences. American Political Science Review, 95, 379-396.

Gimpel, J., \& Chinni, D. (2010). Our patchwork nation: The surprising truth about the "real" America. New York, NY: Penguin Books.

Goldenberg, J.L., Heflick, N.A., Vaes, J., Motyl, M., \& Greenberg, J. (2009). Of mice and men, and objectified women: Terror management as an explanatory framework for infrahumanization effects. Group Processes and Intergroup Relations, 12, 1-14.

Gosling, S. D., Ko, S. J., Mannarelli, T., \& Morris, M. E. (2002). A room with a cue: Personality judgments based on offices and bedrooms. Journal of Personality and Social Psychology, 82, 379-398. 
Graham, J., Haidt, J., Koleva, S., Motyl, M., Iyer, R., Wojcik, S. P., \& Ditto, P. H. (2013). Moral Foundations Theory: The pragmatic validity of moral pluralism. Advances in Experimental Social Psychology.

Graham, J., Haidt, J., \& Nosek, B. (2009). Liberals and conservatives use different sets of moral foundations. Journal of Personality and Social Psychology, 96, 1029-1046.

Graham, J., Nosek, B. A., Haidt, J., Iyer, R., Koleva, S., \& Ditto, P. H. (2011). Mapping the moral domain. Journal of Personality and Social Psychology, 101, 366-385.

Guillaume, Y. R. F., Brodbeck, F. C., \& Riketta, M. (2012). Surface- and deep-level dissimilarity effects on social integration and individual effectiveness related outcomes in work groups: A meta-analytic integration. Journal of Occupational and Organizational Psychology, 85, 80-115.

Haidt, J. (2001). The emotional dog and its rational tail: A social intuitionist approach to moral judgment. Psychological Review, 108, 814-834.

Haidt, J. (2007). The new synthesis in moral psychology. Science, 316, 998-1002.

Haidt, J., Rosenberg, E., \& Hom, H. (2003). Differentiating diversities: Moral diversity is not like other kinds. Journal of Applied Social Psychology, 33, 1-36.

Haidt, J., Seder, P., \& Kesebir, S. (2008). Hive Psychology, Happiness, and Public Policy. Journal of Legal Studies, 37, S133-S156

Hardin, C. D., \& Higgins, E. T. (1996). Shared reality: How social verification makes the subjective objective. In R. M. Sorrentino \& E. T. Higgins (Eds.), Handbook of motivation and cognition, Vol. 3: The interpersonal context (pp. 28-84). New York, NY: The Guilford Press.

Hartel, C. E. J., \& Fujimoto, Y. (1999). Explaining why diversity sometimes has positive effects in organizations and sometimes has negative effects in organizations: The perceived dissimilarity openness moderator model. Academy of Management Best Papers Proceedings.

Harton, H. C., \& Bullock, M. (2007), Dynamic social impact: A theory of the origins and evolution of culture. Social and Personality Psychology Compass, 1, 521-540. doi: 10.1111/j.1751-9004.2007.00022.x.

Haslam, S. A., Jetten, J., Postmes, T., \& Haslam, C. (2008). Social identity, health and wellbeing: An emerging agenda for applied psychology. Applied Psychology, 58, 1-23.

Hess, J. Z., Rynczak, D., Minarik, J. D., \& Landrum-Brown, J. (2010). Alternative settings for liberal-conservative exchange: Examining an undergraduate dialogue course. Journal of Community \& Applied Social Psychology, 20, 156-166.

Hobman, E. V., Bordia, P., \& Gallois, C. (2003). Consequences of feeling dissimilar from others in a work team. Journal of Business and Psychology, 17, 301-325.

Huckfeldt, R., Mendez, J. M., \& Osborn, T. (2004). Disagreement, ambivalence, and engagement: The political consequences of heterogeneous networks. Political Psychology, 25, 65-95.

Inglehart, R. F. (2008). Changing values among western publics from 1970 to 2006. West European Politics, 31, 130-146.

Jackson, S. E., Brett, J. F., Sessa, V. I., Cooper, D. M., Julin, J. A., \& Peyronnin, K. (1991). Some differences make a difference: Individual dissimilarity and group heterogeneity as correlates of recruitment, promotions, and turnover. Journal of Applied Psychology, 76, 675-689. 
Jehn, K. A., Chadwick, C., \& Thatcher, S. M. B. (1997). To agree or not to agree: The effects of value congruence, individual demographic dissimilarity, and conflict on workgroup outcomes. International Journal of Conflict Management, 8, 287-305.

Jokela, M. (2009). Personality predicts migration within and between US states. Journal of Research in Personality, 43, 79-83.

Karylowski, J. (1976). Self-esteem, similarity, liking and helping. Personality and Social Psychology Bulletin, 2, 71-74.

Kendal, J., Tehrani, J. J., \& Odling-Smee, J. (2011). Human niche construction in interdisciplinary focus. Philosophical Transactions of the Royal Society, 366, 785-792.

Kenrick,D. T., Griskevicius, V., Neuberg, S. L., \& Schaller, M. (2010). Renovating the pyramid of needs: Contemporary extensions built upon ancient foundations. Perspectives on Psychological Science, 5, 292-314.

Kim, J. (2005). "Bowling together" isn't a cure-all: The relationship between social capital and political trust in South Korea. International Political Science Review, 26, 193-213.

Kim, H. S., Sherman, D. K., Ko, D., \& Taylor, S. E. (2006). Pursuit of comfort and pursuit of harmony: Culture, relationships, and social support seeking. Personality and Social Psychology Bulletin, 32, 1595-1607.

Koleva, S. P., Graham, J., Ditto, P., Iyer, R., \& Haidt, J. (2012). Tracing the threads: how five moral concerns (especially Purity) help explain culture war attitudes. Journal of Research in Personality, 46(2), 184-194.

Kruglanski, A. W., \& Fishman, S. (2006). The psychology of terrorism: "Syndrome" versus "tool" perspectives. Terrorism and Political Violence, 18, 193-215.

Kunda, Z. (1990). The case for motivated reasoning. Psychological Bulletin, 108, 480-498.

Leary, M. R. (2009). Affiliation, acceptance, and belonging: The pursuit of interpersonal connection. In S. Fiske, D. Gilbert, \& G. Lindzey (Eds.), Handbook of social psychology (4th ed.).

Lenzi, M., Colucci, E., \& Minas, H. (2012). Suicide, culture, and society from a cross-national perspective. Cross-Cultural Research, 46, 50-71.

Leone, C. (1989). Self-generated attitude change: Some effects of thought and dogmatism on attitude polarization. Personality and Individual Differences, 10, 1243-1252.

Levendusky, M. (2009). The partisan sort: How liberals became Democrats and conservatives became Republicans. Chicago, IL: University of Chicago Press.

Lewin, K. (1951). Field theory in social science: selected theoretical papers (Edited by Dorwin Cartwright.).

Lewis, N. M. (2012). Remapping disclosure: gay men's segmented journeys of moving out and coming out. Social \& Cultural Geography, 13, 211-231.

Lewis, V. A. (2012). Social energy and racial segregation in the university context. Social Science Quarterly, 93, 270-290.

Lick, D. J., Tornello, S. L., Riskind, R. G., Schmidt, K. M., \& Patterson, C. J. (2012). Social climate for sexual minorities predicts well-being among heterosexual offspring of lesbian and gay parents. Sexuality Research and Social Policy.

Lim, M., Metzler, R., \& Bar-Yam, Y. (2007). Global pattern formation and ethnic/cultural violence. Science, 317, 1540-1544.

Lun, V. M., \& Bond, M. H. (2006). Achieving relationship harmony in groups and its consequences for group performance. Asian Journal of Social Psychology, 9, 195-202. 
Lupia, A. (2006). How elitism undermines the study of voter competence. Critical Review, 18, 217-232.

MacKinnon, S. P., Jordan, C. H., \& Wilson, A. E. (2011). Birds of a feather sit together: Physical similarity predicts seating choice. Personality and Social Psychology Bulletin, 37, 879892.

Major, B., \& O’Brien, L. T. (2005). The social psychology of stigma. Annual Review of Psychology, 56, 393-421.

Maslow, A. H. (1943). A theory of human motivation. Psychological Review, 50, 370.

McClurg, S. D. (2006). Political disagreement in context: The conditional effect of neighborhood context, disagreement and political talk on electoral participation. Political Behavior, 28, 349-366.

McPherson, M., Smith-Lovin, L., \& Cook, J. M. (2001). Birds of a feather: Homophily in social networks. Annual Review of Sociology, 27, 415-444.

Moscovici, S., \& Zavalloni, M. (1969). The group as a polarizer of attitudes. Journal of Personality and Social Psychology, 12, 125.

Moscovici, S., Zavalloni, M., \& Louis-Guerin, C. (1972). Studies on polarization of judgments: I. Group effects on person perception. European Journal of Social Psychology, 2, 87-91.

Moscovici, S., Zavalloni, M., Weinberger, M. (1972). Studies on polarization of judgments: II. Person perception, ego involvement and group interaction. European Journal of Social Psychology, 2, 92-94.

Motyl, M. (2014). "If he wins, I'm moving to Canada": Ideological migration threats following the 2012 U.S. Presidential election. Analyses of Social Issues and Public Policy.

Motyl, M., Hart, J., Pyszczynski, T., Weise, D., Cox, C., Maxfield, M., \& Siedel, A. (2011). Subtle priming of shared human experiences eliminates threat-induced negativity toward Arabs, immigrants, and peace-making. Journal of Experimental Social Psychology, 47, 1179-1184.

Motyl, M., \& Iyer, R. (2013). Will the real fundamental difference underlying ideology please stand up? Behavioral and Brain Sciences.

Motyl, M., Iyer, R., Oishi, S., Trawalter, S., \& Nosek, B. A. (2014). How ideological migration geographically segregates groups. Journal of Experimental Social Psychology, 51, 1-14.

Motyl, M., \& Pyszczynski, T. (2010). The existential underpinnings of the cycle of terrorist and counterterrorist violence and pathways to peaceful resolutions. International Review of Social Psychology, 3, 267-291.

Motyl, M., Rothschild, Z., \& Pyszczynski, T. (2009). The cycle of violence and pathways to peace. Organisational Transformation and Social Change, 6, 153-170.

Murphy, M. C., Steele, C. M., \& Gross, J. G. (2007). Signaling threat: How situational cues affect women in math, science, and engineering settings. Psychological Science, 18, 879885.

Mutz, D. C. (2006). Hearing the other side: Deliberative versus participatory democracy. New York, NY: Cambridge University Press.

Oishi, S. (2010). The psychology of residential mobility: Implications for the self, social relationships, and well-being. Perspectives on Psychological Science, 5, 5-21.

Oishi, S., \& Graham, J. (2010). Social ecology: Lost and found in psychological science. Perspectives on Psychological Science, 5, 356-377.

Oyserman, D., Brickman, D., Bybee, D., \& Celious, A. (2006). Fitting in matters: Markers of ingroup belonging and academic outcomes. Psychological Science, 17, 854-861. 
Page-Gould, E., Mendoza-Denton, R., \& Tropp, L. R. (2008). With a little help from my crossgroup friend: Reducing anxiety in intergroup contexts through cross-group friendships. Journal of Personality and Social Psychology, 95, 1080-1094.

Paicheler, G. (1979). Polarization of attitudes in homogeneous and heterogeneous groups. European Journal of Social Psychology, 9, 85-96.

Park, N., \& Peterson, C. (2010). Does it matter where we live? The urban psychology of character strengths. American Psychologist, 65, 535-547.

Pelled, L. H. (1996). Demographic diversity, conflict, and work group outcomes: An intervening process theory. Organization Science, 7, 615-631.

Pettigrew, T. F., \& Tropp, L. R. (2006). A meta-analytic test of intergroup contact theory. Journal of Personality and Social Psychology, 90, 751-783.

Petty, R. E., \& Krosnick, J. A. (1995). Attitude strength: An overview. In R. E. Petty \& J. A. Krosnick (Eds.), Attitude strength: Antecedents and consequences (pp. 1-24). Mahwah, NJ: Lawrence Erlbaum.

"Political Polarization in the American Public" (2014, June 12). Pew Research Center. Retrieved January 15, 2015 from http://www.people-press.org/2014/06/12/political-polarization-inthe-american-public/.

Poteat, V. P., Mereish, E. H., Liu, M. L., \& Nam, J. S. (2011). Can friendships be bipartisan? The effects of political ideology on peer relationships. Group Processes \& Intergroup Relations, 14, 819-834.

Putnam, R. D. 2000. Bowling Alone: The Collapse and Revival of American Community. New York: Simon \& Schuster.

Putnam, R. D. (2007). E Pluribus Unum: Diversity and community in the twenty-first century: The 2006 Johan Skytte Prize Lecture. Scandinavian Political Studies, 30, 137-174.

Pyszczynski, T., Henthorn, C., Motyl, M., Gerow, K. (2010). Is Obama the Anti-Christ? Racial priming, extreme criticisms of Barack Obama, and attitudes toward the 2008 US presidential candidates. Journal of Experimental Social Psychology, 46, 863-866.

Pyszczynski, T., Motyl, M., \& Abdollahi, A. (2009). Righteous violence: Killing for god, country, freedom, and justice. Behavioral Sciences of Terrorism and Political Aggression, 1, 12-39.

Rentfrow, P. J., Gosling, S. D., \& Potter, J. (2008). A Theory of the emergence, persistence, and expression of geographic variation in psychological characteristics. Perspectives on Psychological Science, 3, 339-369.

Rutchick, A. M., Smyth, J. M., \& Konrath, S. (2009). Seeing red (and blue): Effects of electoral college depictions on political group perception. Analyses of Social Issues and Public Policy, 9, 269-282.

Sampson, R. J., \& Raudenbush, S. W. (2004). Seeing disorder: Neighborhood stigma and the social construction of "broken windows." Social Psychology Quarterly, 67, 319-342.

Schkade, D., Sunstein, C. R., \& Hastie, R. (2010). When deliberation produces extremism. Critical Review, 22, 227-252.

Schmitt, M. T., Davies, K., Hung, M., \& Wright, S. C. (2010). Identity moderates the effects of Christmas displays on mood, self-esteem, and inclusion. Journal of Experimental Social Psychology, 46, 1017-1022.

Seder, J. P., \& Oishi, S. (2009). Ethnic/racial homogeneity in college students' Facebook friendship networks and subjective well-being. Journal of Research in Personality, 43, 438-443. 
Seyle, D. C., \& Newman, M. L. (2006). A house divided? The psychology of red and blue America. American Psychologist, 61, 571-580.

Sheldon, K. M., \& Bettencourt, B. A. (2010). Psychological need-satisfaction and subjective well-being within social groups. British Journal of Social Psychology, 41, 25-38.doi: $10.1348 / 014466602165036$

Sherif, M. (1936). The psychology of social norms.

Sherif, M. (1958). Superordinate goals in the reduction of intergroup conflict. The American Journal of Sociology, LXIII, 349-356.

Smart, M. J., \& Klein, N. J. (2013). Neighborhoods of Affinity: Social Forces and Travel in Gay and Lesbian Neighborhoods. Journal of the American Planning Association, 79, 110-124.

Sunstein, C. R., Schkade, D., \& Ellman, L. (2004). Ideological voting on federal courts of appeals: A preliminary investigation. Virginia Law Review, 90, 301-354.

Tetlock, P. E., Kristel, O. V., Elson, B., Lerner, J. S., \& Green, M. C. (2000). The psychology of the unthinkable: Taboo trade-offs, forbidden base rates, and heretical counterfactuals. Journal of Personality and Social Psychology, 78, 853-870.

Tetlock, P. E., Peterson, R. S., McGuire, C., Chang, S., \& Feld, P. (1992). Assessing political group dynamics: A test of the groupthink model. Journal of Personality and Social Psychology, 63, 403-425.

Trawalter, S., \& Hoffman, K. M. (2012). Space for diversity? Use of public space and sense of place in higher education. Unpublished manuscript, University of Virginia.

Trawalter, S., Richeson, J. A., \& Shelton, J. N. (2009). Predicting behavior during interracial interactions: A stress and coping approach. Personality and Social Psychology Review, 13, 243-268.

Vail III, K. E., Arndt, J., Motyl, M., \& Pyszczynski, T. (2009). Compassionate values and presidential politics: Mortality salience, compassionate values and support for Barack Obama and John McCain in the 2008 presidential election. Analyses of Social Issues and Public Policy, 9, 255-268.

Vail, K. E., Arndt, J., Motyl, M., \& Pyszczynski, T. (2012). The aftermath of destruction: Images of destroyed buildings increase support for war, dogmatism, and death thought accessibility. Journal of Experimental Social Psychology, 48, 1069-1081.

Van der Vegt, G. S. (2002). Effects of attitude dissimilarity and time on social integration: A longitudinal panel study. Journal of Occupational and Organizational Psychology, 75, 439-452.

Walton, G. M., \& Cohen, G. L. (2011). A brief social-belonging intervention improves academic and health outcomes of minority students. Science, 331, 1447-1451.

Waytz, A., Young, L. L., \& Ginges, J. (2014). Motive attribution asymmetry for love vs. hate drives intractable conflict. Proceedings of the National Academy of Sciences, 111, 1568715692.

Williams, M., \& Dutton, J. E. (1999). Corrosive political climates: The heavy toll of negative political behavior in organizations. In R. E. Quinn, R. M. O'Neill, and L. St. Clair (Eds.), The pressing problems of modern organizations: Transforming the agenda for research and practice (ps. 3-30). New York: American Management Association. 
Figure 1. Ideological Enclavement Theory conceptual model.

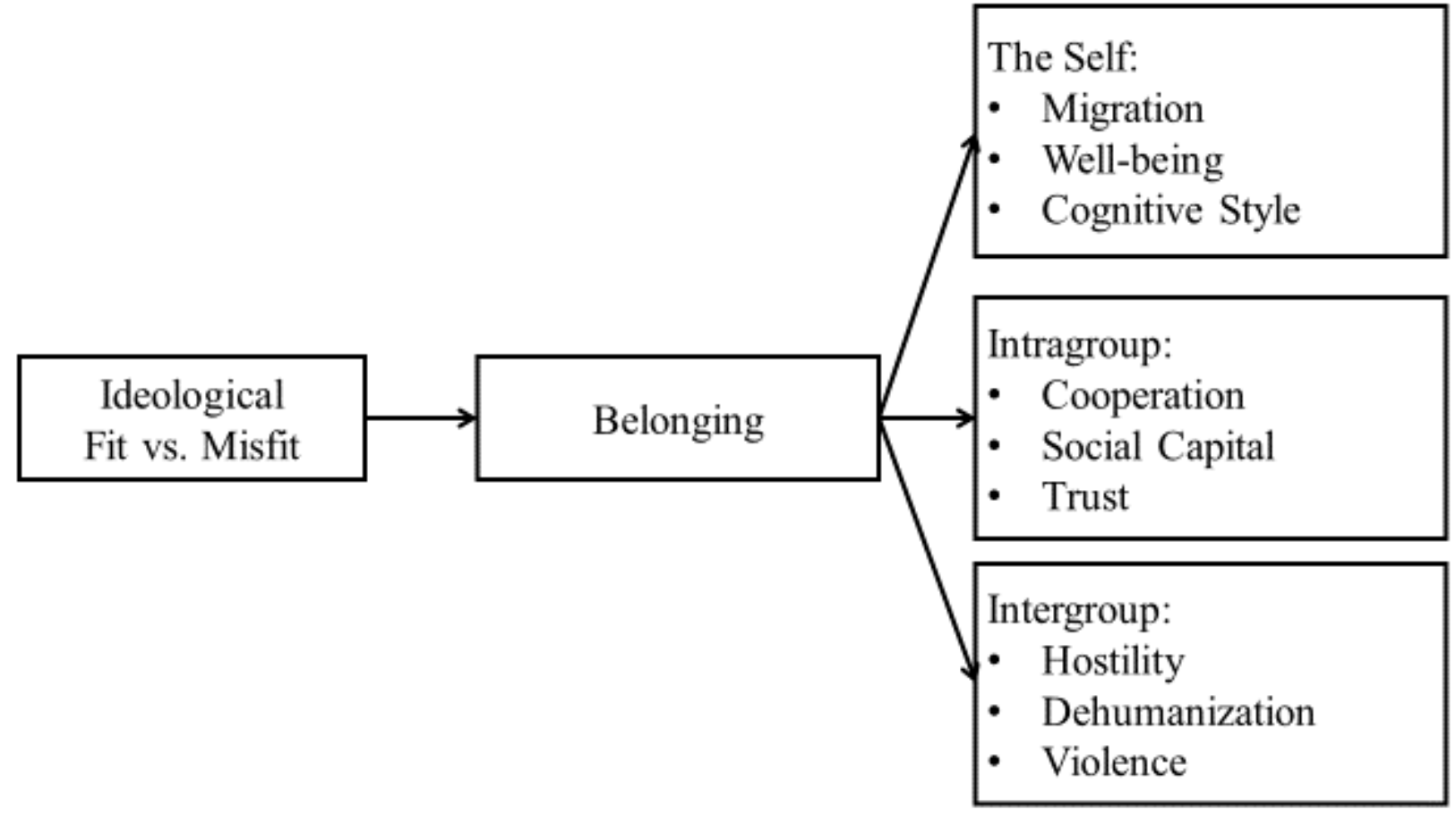

